\title{
Comparison of various activation methods of root canal irrigants for soft-tissue removal
}

\author{
Kun-Hwa Sung ${ }^{1}$, Tae-Young Park², Ho-Keel Hwang ${ }^{2}$, and Hyoung-Hoon Jo ${ }^{2 \star}$ \\ ${ }^{1}$ Ph.D. Student, Department of Conservative Dentistry, School of Dentistry, Chosun University, Gwangju, Republic of Korea \\ ${ }^{2}$ Professor, Department of Conservative Dentistry, School of Dentistry, Chosun University, Gwangju, Republic of Korea
}

\begin{abstract}
The aim of this study was to evaluate the effects of various activation methods on the efficiency of soft-tissue removal in the artificial root canal system. The artificial root canal system, including the isthmus, was fabricated using poly (methyl methacrylate). Grounded pork was filled in the isthmus, soaked with $\mathrm{NaOCl}$ for 5 minutes, and followed by various irrigation and activation procedures. Group 1 performed irrigation using a side-vented needle and syringe, and group 2 performed sonic activation using an activator. Furthermore, group 3 performed ultrasonic activation using EndoSonic PS tip with EMS scaler engine. Subsequently, the time taken for the complete removal of grounded pork from the isthmus was measured. The sonic and ultrasonic activation groups showed significantly higher irrigation efficacy than those without activation. The ultrasonic activation group showed a higher efficiency when compared with the sonic activation group. In conclusion, additional activation of irrigants can improve the efficiency of soft-tissue removal in anatomical structures, such as the isthmus.
\end{abstract}

Key Words: Canal irrigation; Root canal irrigants; Sodium hypochlorite; Sonic activation; Ultrasonic

(c) This is an open-access article distributed under the terms of the Creative Commons Attribution Non-Commercial License (http://creativecommons.org/licenses/by-nc/4.0) which permits unrestricted noncommercial use, distribution, and reproduction in any medium, provided the original work is properly cited.

\section{Introduction}

For successful endodontic treatment, complete removal of organic substance from a root canal is essential. However, complete cleaning of a root canal is challenging because of its anatomical complexity [1]. Incomplete cleaning may lead to problems associated with reinfection, following the endodontic treatment [1,2].

In modern endodontic treatment, the removal of organic substance from a root canal is achieved by a combination of mechanical (Gates-Glidden burs, hand-files, Ni-
Ti files, etc.) and chemical methods (sodium hypochlorite, ethylenediaminetetraacetic acid, etc.). A Ni-Ti file has only limited effect in removal of organic substance that is located in the root canal, and cannot remove the organic substance or debris mixed with organics and inorganics from areas which are difficult to be accessed, such as the isthmus. Root canal cleaning solutions are used to remove organic substance and debris from areas that are difficult to access mechanically. Sodium hypochlorite $(\mathrm{NaOCl})$ is a representative cleaning solution used in endodontic treatment. It has the property of dissolving organic tissue, and

Received January 17, 2021; Revised February 24, 2021; Accepted February 26, 2021

*Corresponding author: Hyoung-Hoon Jo, Department of Conservative Dentistry, School of Dentistry, Chosun University, 303 Pilmun-daero, Dong-gu, Gwangju 61452, Republic of Korea.

Tel: +82-62-220-3848, Fax: +82-62-223-9064, E-mail: joyendo@hanmail.net

Copyright @ 2021, Oral Biology Research Institute 
possess antibacterial properties [3-5]. In conventional nonsurgical endodontic treatment, $\mathrm{NaOCl}$ is applied by placing a needle in the root canal and generating positive pressure in the syringe. $\mathrm{NaOCl}$ chemically dissolves the organic content, and mechanically removes the inorganic content from the root canal.

However, using positive pressure for intracanal cleaning is impeded by vapor lock, and has the limitation of poor access to anatomical structures, such as the isthmus [1]. In order to overcome these limitations, and for improving the root canal cleaning efficacy, a method of activating the cleaning solution using sonic and ultrasonic devices was introduced [6,7]. Sonic and ultrasonic devices generate vibrations within the root canal, to enhance the efficiency of $\mathrm{NaOCl}$ [8]. An activated cleaning solution is known to enhance the intracanal cleaning. Previous studies have been conducted mainly on the removal of inorganic substances from complex anatomical structures in the root canals, such as the isthmus, but there is a lack of research on the removal of organic substances from the anatomical structures $[1,2,9,10]$.

Therefore, the purpose of this study was to evaluate the effects of conventional irrigation without activation, sonic activation, ultrasonic activation methods on the removal efficiency of organic substances from complex anatomical structures.

\section{Materials and Methods}

\section{Specimen preparation}

Transparent acrylate blocks were fabricated to replicate the standardized root canal system and isthmus. These blocks were fabricated by computerized numerical control milling, using poly-methyl-methacrylate (PMMA) materials. Each block consisted of two parts, and was designed to be assembled using self-tapping bolts. The root canal was formed in the long-axis direction, along the inner surface of each block. When two blocks were assembled, an intact root canal shape was created. A root canal formed by the assembly of the two blocks had an apical diameter of 0.3 $\mathrm{mm}$, a length of $15 \mathrm{~mm}$, and a 0.06 taper. On one side of the block, a groove was formed $2 \mathrm{~mm}$ away from the apex, to reproduce the isthmus in the root canal. This isthmus was designed to have a length of $4 \mathrm{~mm}$, a depth of $0.5 \mathrm{~mm}$, and a width of $0.3 \mathrm{~mm}$. In each block, four holes for the assembly of the blocks were formed, and four self-tapping bolts were used for disassembling and assembling (Fig. 1).

A sand-like mixture made from grounded pork was placed inside the isthmus, which was used to reproduce the organic substance remaining after root canal shaping using a Ni-Ti file. Food coloring agent was added to improve the visibility of minced pork tissue (Fig. 2). Forty-five root canal models divided into three groups.

\section{Root canal irrigation and activation protocols}

Root canal cleaning models were divided into three

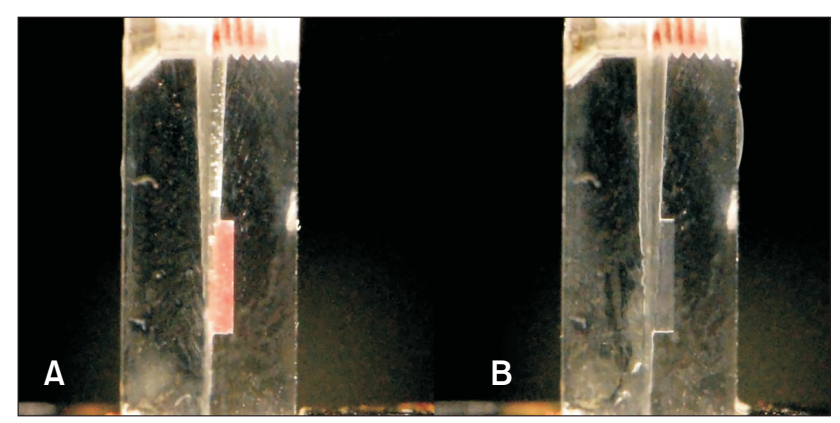

Fig. 2. Soft tissue dissolution inside the isthmus. (A) Before removing the soft tissue. (B) After removing the soft tissue.

\footnotetext{
Lateral view. (B) Frontal view. (C) Perspective view.
}

Fig. 1. Experimental model containing root canal with isthmus. (A) 
groups, depending on the activation of the cleaning solution. A 2.5\% NaOCl (Duksan, Seoul, Korea) was used as the cleaning solution in all experimental groups. After minced pork tissue was placed inside the isthmus, each block was assembled using self-tapping bolts. In order to recreate the soft tissue exposed to $\mathrm{NaOCl}$ during a real endodontic treatment, $\mathrm{NaOCl}$ was applied in the root canal and was left to soak for 5 minutes, before root canal cleaning and activation was carried out.

The root canal models were divided into the following three groups:

Group 1: Conventional needle Irrigation group

In group 1 (Con, $\mathrm{n}=15)$, root canal cleaning was done using a $27 \mathrm{G}$ side-vented irrigation needle (Union Tech, Seoul, Korea), and a $20 \mathrm{~mL}$ syringe (Sungshin, Seoul, Korea). The tip of the needle was placed $1 \mathrm{~mm}$ away from the apex of the root canal, and then repeatedly moved up and down. The $\mathrm{NaOCl}$ solution was injected at a constant rate of approximately $10 \mathrm{~mL}$ per minute. Root canal cleaning was performed until all of the soft tissue in the isthmus was dissolved and could not be visually identified.

Group 2: Sonic activation group

In group 2 (EA, $\mathrm{n}=15), \mathrm{NaOCl}$ solution was activated using EndoActivator (Dentsply Tulsa Dental Specialties, OK, USA). \#25/.04 activation tip provided for EndoActivator was used in this experiment. The tip of the EndoActivaor was placed $1 \mathrm{~mm}$ away from the apex, and during activation, vertical movement was performed according to the manufacturer's instructions. After activating for 50 seconds, $\mathrm{NaOCl}$ was supplied for additional 10 seconds, using a side vented needle and a syringe. This process was repeated until the soft tissues inside the isthmus were dissolved and not visually identified.

Group 3: Ultrasonic activation group

In group 3 (PS, n=15), $\mathrm{NaOCl}$ was activated using EndoSonic PS tip (SelectD, Seoul, Korea), and an ultrasonic scaler (EMS, Nyon, Switzerland). The EndoSonic PS tip was used in conjunction with the EMS ultrasonic scaler. According to the manufacturer, the oscillation frequency of this instrument was $30 \mathrm{kHz}$. The EndoSonic PS tip was placed 1 $\mathrm{mm}$ away from the apex, and activation was performed in the same protocol as in group 2.

\section{Image evaluation and statistical analysis}

Intracanal irrigation procedures in all three groups were recorded as video files, using a D3300 digital single-lens reflex camera (Nikon, Tokyo, Japan). The recorded video files were transferred to a computer, and were analyzed by two observers. The time taken until the organic substance inside the isthmus was completely dissolved and was not visually identifiable, was measured in seconds (Fig. 2).

Data were analyzed with SPSS Statistics for Windows, Version 17.0 (SPSS Inc., Chicago, IL, USA). Kruskal-Wallis test and Mann-Whitney U-test were used for comparison of average dissolution time. The significance level was set at $p=0.05$.

\section{Results}

Table 1 shows the mean time for removal of soft tissue in each experimental group. The statistical significant differences between the groups are shown in Fig. 3 .

Groups which were activated using sonic and ultrasonic devices (Group 1 and 2) showed significantly shorter mean removal time than those without activation (Group 1) ( $p \leq$ 0.01). In the comparison between the groups using the ultrasonic device and the sonic device, the ultrasonic device group showed a significantly shorter mean removal time $(p$ $\leq 0.01$.

\section{Discussion}

After endodontic treatment, pulpal debris or bacterial remnants may remain within the complex anatomical structures of the root canal, such as the isthmus. This can lead to reinfection, resulting in failure of the root canal

Table 1. Mean removal time of soft tissue from the isthmus

\begin{tabular}{cc}
\hline Group & Time (sec) \\
\hline Group 1 (Con) & $266 \pm 45$ \\
Group 2 (EA) & $177 \pm 21$ \\
Group 3 (PS) & $41 \pm 14$ \\
\hline
\end{tabular}

Values are presented as mean \pm standard deviation.

Con, conventional needle irrigation; EA, EndoActivator; PS, EndoSonic PS tip. 


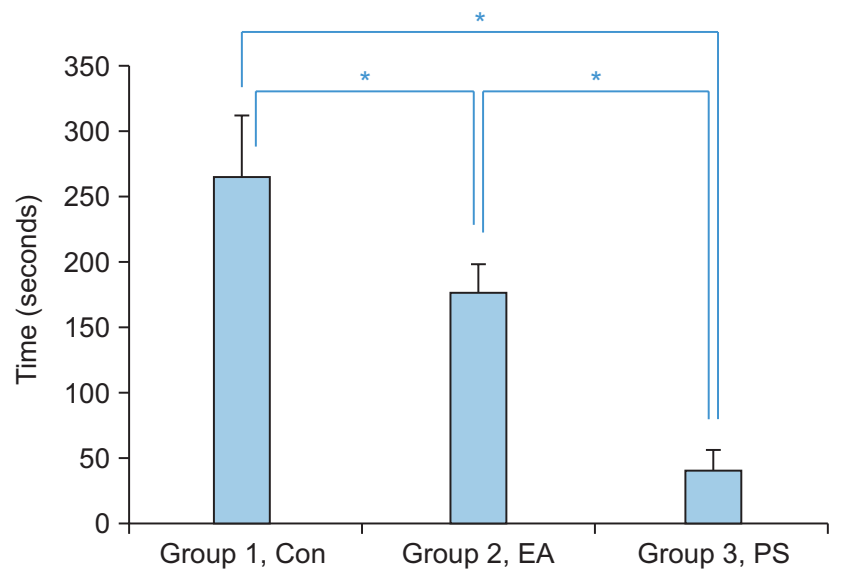

Fig. 3. Comparison of mean removal time of soft tissue between groups. Con, conventional needle irrigation; EA, EndoActivator; PS, EndoSonic PS tip. ${ }^{*}$ Marks means significant difference between groups $(\mathrm{p}<0.05)$.

treatment [11]. Peters et al. [12] found that at least 35\% of the root canal walls remained untouched after $\mathrm{Ni}-\mathrm{Ti}$ instrumentation. For tissues that are not mechanically removed, the cleaning solution dissolves organic tissues, kills microbes, and removes smear layers to increase the success rate of root canal treatment $[5,13,14]$. Conventional irrigation method using syringes and needles are known to be less effective for complex anatomical structures in the root canal $[15,16]$. To overcome this weakness, a method of activating the irrigation solution using sound and ultrasound waves has been developed. Various studies have shown that activation of irrigation solutions using sonic and ultrasonic devices improves root canal cleaning, as well as the anti-bacterial efficiency $[8,17,18]$.

EndoActivator is an instrument that activates the irrigation solution using sonic vibration (2-3 kHz frequency). EndoActivator is composed of two parts: a handle, that generates sonic vibrations; and a polymer tip, that transmits these vibrations into the root canal. EndoSonic PS tips are used in connection with conventional ultrasonic instruments. In this experiment, an EMS ultrasonic scaler was used. Ultrasonic devices show a frequency of $25-40 \mathrm{kHz}$, which is much higher than the frequency of sonic devices. EndoSonic PS tip is a passive ultrasonic irrigation system, using a flexible polymer tip that can deliver activation energy up to the root apex. In contrast to the active ultrasonic irrigation system, the passive system has the advantage of maintaining the shape of the root canal after irrigation $[19,20]$. Activation of the irrigation solution is known to be achieved through acoustic streaming and cavitation mechanism. Acoustic streaming refers to the generation of fluid circulation or vortex around the vibrating mechanism, and cavitation refers to the formation of air chambers within the fluid or the expansion, contraction, or rupture of air bubbles [2]. Activation through acoustic streaming and cavitation mechanisms improves the cleaning efficiency and, consequently, soft tissue dissolution efficiency in complex anatomical structures, such as the lateral canals and the isthmus [21].

Various studies have been conducted on the activation of root canal irrigants. Existing experimental methods using extracted teeth have limitations, in that it is difficult to obtain a standardized canal morphology, and to observe the inside of the canal in real time, due to the opacity of the tooth structure. The PMMA root canal model has the advantage of obtaining a consistent root canal shape, removing the influence on the type of $\mathrm{Ni}$-Ti file used for the mechanical shaping of the root canal, and not chemically reacting with $\mathrm{NaOCl}$ [22]. In addition, due to the transparency of PMMA, the process of removing the material from the inside of the isthmus can be clearly observed visually [23]. Previous studies have focused on the mechanical removal of minerals, such as dentin residues, from the anatomical structures. However, in this experiment, the mechanical removal and the chemical dissolution of soft tissues could be evaluated using minced pork tissue. However, this research method also has a limitation that it is difficult to clearly distinguish between the chemical solubility, and the mechanical removal ability. Therefore, further study is needed to evaluate the independent effects of irrigation solution activation on chemical removal efficacy.

In the results of this study, the activation of the irrigants using sonic and ultrasonic devices showed higher removal efficacy, as compared to the conventional irrigation methods using syringes and needles. This result was in agree with a previous study which has shown that the activation of the cleaning solution for the removal of minerals from the isthmus is more effective, as compared to the conventional root canal cleaning method [10]. The efficacy of the root canal cleaning is determined by combining the chemi- 
cal tissue dissolution ability of the cleaning solution, and the mechanical root canal cleaning ability of the irrigants, as well as the cleaning device [8]. In this experiment, the use of ultrasonic device showed higher root canal cleaning efficiency than the methods used in the other two groups. This difference appears to be due to the higher frequency of the ultrasonic activation system, delivering more energy than the sonic activation system. The video analysis showed that the ultrasonic device displayed better mechanical removal of tissues from complex anatomical structures, such as the isthmus, and the soft tissue residues that had been removed from the isthmus and moved into the root canal, were dissolved more quickly. On the other hand, in the conventional group using needles and syringes, and in the group using sonic devices, the chemical dissolution capacity of $\mathrm{NaOCl}$ appeared to be an important factor in the root canal cleaning rather than the mechanical cleaning ability. However, these results are limited for anatomical structures like the isthmus, and may vary depending on experimental conditions such as various $\mathrm{NaOCl}$ concentrations and anatomic complexities. Further studies with various conditions and anatomic structures are required to reproduce the actual clinical situation. In this experiment, minced pork tissue was used to recreate the residues that remain inside the isthmus following endodontic treatment. However, in the actual endodontic treatment, soft tissues such as remaining pulpal tissue, minerals, and bacterial remnants may be mixed inside the isthmus. Therefore, there is a need for an evaluation method that can separately evaluate the chemical solubility and mechanical removal ability. Finally, the PMMA block used in this experiment has the advantage of recreating the standardized root canal system, but it is limited in the recreation of the dentinal tubule, which is closely related to the success of the endodontic treatment. Therefore, it is necessary to develop a model that can reproduce the dentinal tubule simultaneously with the standardized canal morphology.

Within the study limitations, when ultrasonic and sonic devices were used to activate the root canal irrigants, organic substances in the isthmus were removed more efficiently, than when only the needle and syringe were used to clean the root canal. Comparing the two activation methods, removal of organic substances was more efficient when ultrasonic devices were used.

\section{Acknowledgements}

This study was supported by research fund from Chosun University Dental Hospital, 2019.

\section{Conflicts of Interest}

The authors declare that they have no competing interests.

\section{ORCID}

\author{
Kun-Hwa Sung \\ https://orcid.org/0000-0001-5445-9923 \\ Tae-Young Park \\ http://orcid.org/0000-0002-0752-681X \\ Ho-Keel Hwang \\ http://orcid.org/0000-0003-3237-232X \\ Hyoung-Hoon Jo \\ http://orcid.org/0000-0003-3566-1821
}

\section{References}

1. Nagendrababu V, Jayaraman J, Suresh A, Kalyanasundaram S, Neelakantan P. Effectiveness of ultrasonically activated irrigation on root canal disinfection: a systematic review of in vitro studies. Clin Oral Investig 2018;22:655-670. doi: 10.1007/s00784-018-2345-x.

2. Jiang LM, Verhaagen B, Versluis M, van der Sluis LW. Evaluation of a sonic device designed to activate irrigant in the root canal. J Endod 2010;36:143-146. doi: 10.1016/ j.joen.2009.06.009.

3. Byström A, Sundqvist G. Bacteriologic evaluation of the effect of 0.5 percent sodium hypochlorite in endodontic therapy. Oral Surg Oral Med Oral Pathol 1983;55:307-312. doi: 10.1016/0030-4220(83)90333-x.

4. Hand RE, Smith ML, Harrison JW. Analysis of the effect of dilution on the necrotic tissue dissolution property of sodium hypochlorite. J Endod 1978;4:60-64. doi: 10.1016/ S0099-2399(78)80255-6.

5. Moorer WR, Wesselink PR. Factors promoting the tissue dissolving capability of sodium hypochlorite. Int Endod J 1982;15:187-196. doi: 10.1111/j.1365-2591.1982. tb01277.x.

6. Mohammadi Z. Sodium hypochlorite in endodontics: an update review. Int Dent J 2008;58:329-341. doi: 10.1111/ 
j.1875-595x.2008.tb00354.x.

7. Stojicic S, Zivkovic S, Qian W, Zhang H, Haapasalo M. Tissue dissolution by sodium hypochlorite: effect of concentration, temperature, agitation, and surfactant. J Endod 2010;36:1558-1562. doi: 10.1016/j.joen.2010.06.021.

8. Lee SJ, Wu MK, Wesselink PR. The efficacy of ultrasonic irrigation to remove artificially placed dentine debris from different-sized simulated plastic root canals. Int Endod J 2004;37:607-612. doi: 10.1111/j.1365-2591.2004.00857.x.

9. Karade P, Chopade R, Patil S, Hoshing U, Rao M, Rane N, Chopade A, Kulkarni A. Efficiency of different endodontic irrigation and activation systems in removal of the smear layer: a scanning electron microscopy study. Iran Endod J 2017;12:414-418. doi: 10.22037/iej.v12i4.9571.

10. Plotino G, Grande NM, Mercade M, Cortese T, Staffoli S, Gambarini G, Testarelli L. Efficacy of sonic and ultrasonic irrigation devices in the removal of debris from canal irregularities in artificial root canals. J Appl Oral Sci 2019;27:e20180045. doi: 10.1590/1678-7757-2018-0045.

11. De-Deus G, Barino B, Zamolyi RQ, Souza E, Fonseca A Jr, Fidel S, Fidel RA. Suboptimal debridement quality produced by the single-file F2 ProTaper technique in ovalshaped canals. J Endod 2010;36:1897-1900. doi: 10.1016/ j.joen.2010.08.009.

12. Peters OA, Schönenberger K, Laib A. Effects of four Ni-Ti preparation techniques on root canal geometry assessed by micro computed tomography. Int Endod J 2001;34:221230. doi: 10.1046/j.1365-2591.2001.00373.x.

13. Mader CL, Baumgartner JC, Peters DD. Scanning electron microscopic investigation of the smeared layer on root canal walls. J Endod 1984;10:477-483. doi: 10.1016/S00992399(84)80204-6.

14. Miller TA, Baumgartner JC. Comparison of the antimicrobial efficacy of irrigation using the EndoVac to endodontic needle delivery. J Endod 2010;36:509-511. doi: 10.1016/ j.joen.2009.10.008.

15. Burleson A, Nusstein J, Reader A, Beck M. The in vivo evaluation of hand/rotary/ultrasound instrumentation in necrotic, human mandibular molars. J Endod 2007;33:782-
787. doi: 10.1016/j.joen.2007.04.015.

16. Rosenfeld EF, James GA, Burch BS. Vital pulp tissue response to sodium hypochlorite. J Endod 1978;4:140-146. doi: 10.1016/S0099-2399(78)80129-0.

17. Guo X, Miao H, Li L, Zhang S, Zhou D, Lu Y, Wu L. Efficacy of four different irrigation techniques combined with $60^{\circ} \mathrm{C}$ $3 \%$ sodium hypochlorite and 17\% EDTA in smear layer removal. BMC Oral Health 2014;14:114. doi: 10.1186/14726831-14-114.

18. Rödig T, Sedghi M, Konietschke F, Lange K, Ziebolz D, Hülsmann M. Efficacy of syringe irrigation, RinsEndo and passive ultrasonic irrigation in removing debris from irregularities in root canals with different apical sizes. Int Endod J 2010;43:581-589. doi: 10.1111/j.1365-2591.2010.01721. $\mathrm{x}$.

19. Sabins RA, Johnson JD, Hellstein JW. A comparison of the cleaning efficacy of short-term sonic and ultrasonic passive irrigation after hand instrumentation in molar root canals. J Endod 2003;29:674-678. doi: 10.1097/00004770200310000-00016.

20. Walters MJ, Baumgartner JC, Marshall JG. Efficacy of irrigation with rotary instrumentation. J Endod 2002;28:837839. doi: 10.1097/00004770-200212000-00011.

21. Forghani M, Afshari E, Parisay I, Garajian R. Effect of a passive sonic irrigation system on elimination of Enterococcus faecalis from root canal systems of primary teeth, using different concentrations of sodium hypochlorite: an in vitro evaluation. J Dent Res Dent Clin Dent Prospects 2017;11:177-182. doi: 10.15171/joddd.2017.032.

22. Khalap ND, Kokate S, Hegde V. Ultrasonic versus sonic activation of the final irrigant in root canals instrumented with rotary/reciprocating files: an in-vitro scanning electron microscopy analysis. J Conserv Dent 2016;19:368372. doi: 10.4103/0972-0707.186451.

23. Kim JH, Kim JW, Cho KM, Park SH. The efficacy of ultrasonic irrigation technique on debris removal during root canal treatment. J Dent Rehabil Appl Sci 2017;33:97-105. doi: 10.14368/jdras.2017.33.2.97. 